\title{
Effect of deprivation state on successive negative contrast ${ }^{*}$
}

\author{
CHARLES F. FLAHERTY and JOSEPH KELLY \\ Rutgers-The State University, New Brunswick, N.J. 08903
}

Rats maintained at either $75 \%$ or $90 \%$ of their ad lib weight were trained to run in a straight alley for either a $10-$ or 1-pellet reward. Following 15 days (30 trials) of acquisition training, the 10-pellet groups were shifted to 1 pellet. A significant negative contrast was obtained only with the $75 \%$ rats and only in the goal region of the alley. The effects of deprivation on contrast found in this study were consistent with those found in earlier studies and consistent with the effects of deprivation on a number of other extinction-related phenomena.

When rats are shifted from a large to a small reward in a runway, they tend to run slower following the shift than rats that have experienced only the small reward (Crespi, 1942). Several experiments have indicated that this successive negative contrast effect is likely to occur only under states of at least moderately severe deprivation (Ehrenfreund \& Badia, 1962; Cleland, Williams, \& DiLollo, 1969; Ehrenfreund, 1971). In the present experiment-a partial replication of these earlier studies-we investigated runway behavior in rats maintained at either $75 \%$ or $90 \%$ ad lib weight following a shift from a 10- to a 1-pellet reward.

\section{METHOD}

\section{Subjects}

The Ss were 28 male albino rats of the Sprague-Dawley strain, purchased from Carworth Labs.

\section{Apparatus}

The experiment was conducted in a gray straight runway $243.6 \mathrm{~cm}$ long and equipped to measure start, run, and goal times. A more complete description of the apparatus is available in Flaherty \& Davenport (1972).

\section{Procedure}

The Ss were assigned randomly to the four groups defined by the preshift factorial manipulation of reward magnitude (10 pellets or 1 pellet) and deprivation condition ( $90 \%$ ad lib body weight or $75 \%$ ad lib body weight). The Ss were handled and weighed daily for 10 days while being reduced to their deprivation conditions. On each of 2 pretraining days, Ss were allowed $5 \mathrm{~min}$ exploration of the alley. On the second pretraining day, the Ss were also fed $2045-\mathrm{mg}$ Noyes pellets in their home cages. Experimental training was carried on for 15 days preshift and 7 days postshift. In both phases there were two trials per day, with an intertrial interval of approximately $28 \mathrm{~min}$. On the last preshift trial (Trial 30), the reward for both 10-pellet groups was shifted to 1 pellet and remained at that level throughout the postshift phase.

*Supported by a biological sciences support grant and by a grant from the Rutgers Research Council to the first author. Send reprint requests to Charles F. Flaherty, Department of Psychology, Rutgers-The State University, New Brunswick, New Jersey 08903 .

\section{RESULTS \\ Preshift}

Mean start, run, and goal speeds for the preshift phase are presented in the left-hand portion of Fig. 1. The effects of deprivation were apparent within the first three trials. In all three sections of the runway, the $75 \%$ rats ran faster than the $90 \%$ rats in Block 1 (start speed: $F=7.25, \mathrm{df}=1 / 24, \mathrm{p}<.05 ;$ run speed: $F=11.88$, $\mathrm{df}=1 / 24, \mathrm{p}<.01 ;$ goal speed: $\mathrm{F}=9.34, \mathrm{df}=1 / 24$, $\mathrm{p}<.01)$. There were no effects of reward magnitude, nor was there an interactive effect of the two variables on initial performance.

The effects of reward magnitude and deprivation on terminal preshift performance (Block 10) differed in different sections of the runway. In the start speed measure, reward magnitude and deprivation condition clearly had additive effects (reward: $F=28.62$, $\mathrm{df}=1 / 24, \mathrm{p}<.001 ;$ deprivation: $\mathrm{F}=7.96, \mathrm{df}=1 / 24$, $p<.01$; interaction: $F<1$ ). In the middle section of the alley, only the effect of reward magnitude was significant $(F=11.68, \mathrm{df}=1 / 24, \mathrm{p}<.01)$. In the goal region, there was a significant interaction $(F=8.70$, $\mathrm{df}=1 / 24, \mathrm{p}<.01)$ which clearly reflected the slower running of the $90 \%$ 1-pellet group compared to the other three groups.

\section{Postshift}

The postshift data are clear. The rats maintained at $75 \%$ of ad lib weight and shifted from 10 pellets to 1 pellet showed an increasing trend toward negative contrast as the goal section was approached. In comparison, the rats maintained at $90 \%$ body weight and shifted from 10 pellets to 1 pellet showed no evidence of a negative contrast effect. In fact, the postshift speed of the $90 \%$ rats remained above the unshifted $90 \%$ rats.

These results, apparent in Fig. 1, were supported statistically. Considering first the $75 \%$ rats, in the goal speed measure there was an overall group effect $(F=5.22, \mathrm{df}=1 / 12, \mathrm{p}<.05)$ which indicated that the shifted group ran slower than the unshifted controls. Further analysis of the goal data with Fisher's Isd test $(p=.05)$ indicated that this difference was significant only in the last four postshift blocks. The shifted $75 \%$ rats also dropped below the unshifted controls in the run speed measure; however, this difference failed to reach significance at the .05 level. In the start measure, there was no postshift difference between shifted and unshifted $75 \%$ rats.

Analyses of the data from the $90 \%$ groups showed that the shifted rats did respond to the changed reward conditions by slowing down (linear component of Groups by Blocks interaction, start speed: $F=22.86$, $\mathrm{df}=1 / 72, \mathrm{p}<.005 ;$ run speed: $\mathrm{F}=9.80, \mathrm{df}=1 / 72$, 

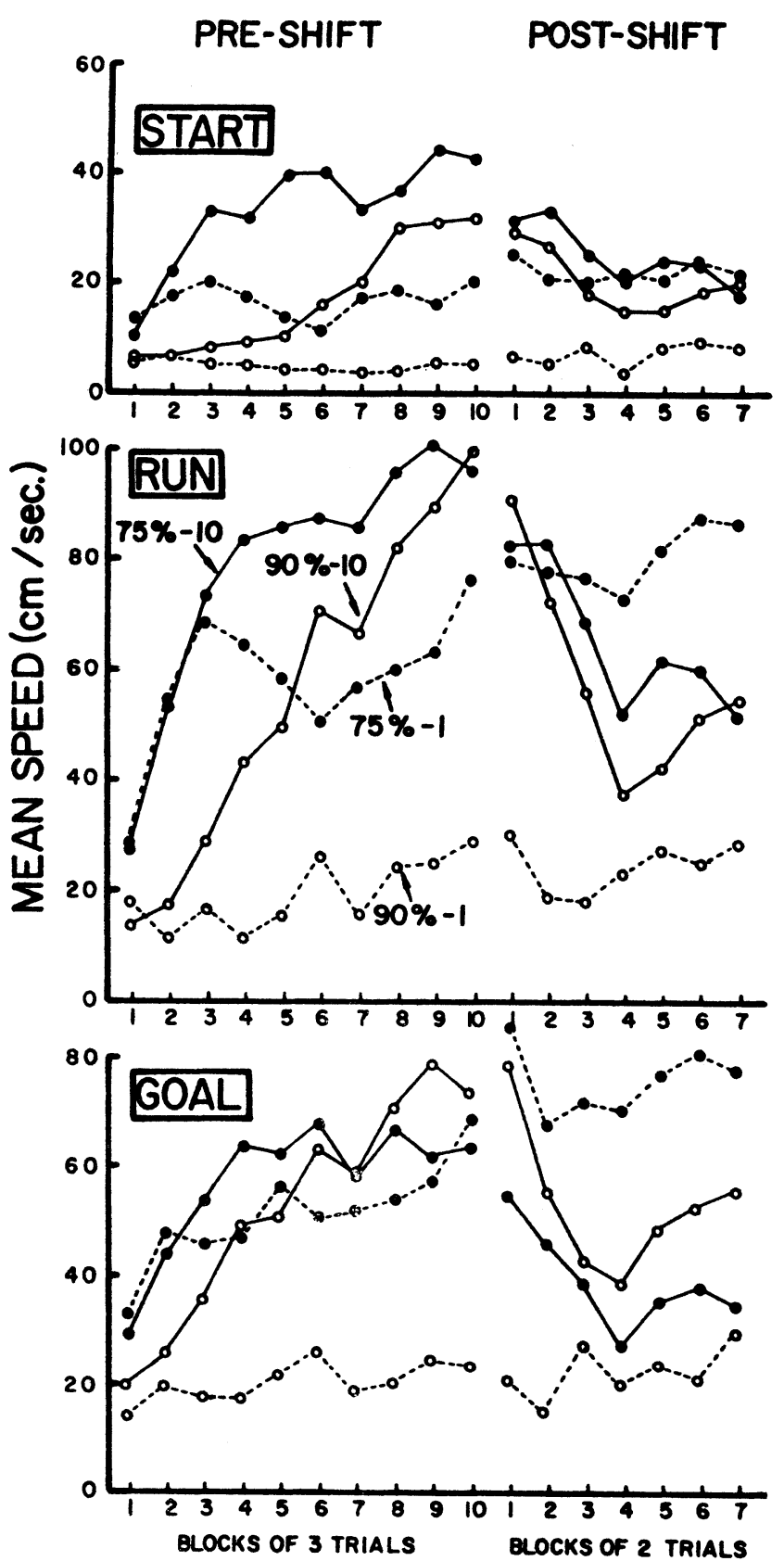

Fig. 1. Mean speed in three runway segments as a function of preshift and postshift deprivation and reinforcement conditions. In the preshift phase, Ss were maintained at either $75 \%$ or $90 \%$ ad lib weight and received either a 10 or a 1-pellet reward. In the postshift phase, deprivation conditions remained the same, but all Ss were shifted to the 1-pellet reward condition.

$p<.005$; goal speed: $F=8.43$, df $=1 / 72, p<.01$ ). However, the shifted rats also showed a leveling off during the postshift phase (quadratic component of Groups by Blocks interaction, start speed: $F=9.08$, $\mathrm{df}=1 / 72, \mathrm{p}<.005 ;$ run speed: $\mathrm{F}=4.77, \mathrm{df}=1 / 72$, $\mathrm{p}<.025$; goal speed: $\mathrm{F}=12.05, \mathrm{df}=1 / 72, \mathrm{p}<.005$ ), and this leveling off tended to occur at a speed above that of the unshifted controls. This latter effect was particularly strong in the goal region, where the shifted $90 \%$ rats ran significantly faster than the unshifted $90 \%$ rats on postshift Blocks 1 and 2, and again on Blocks 5, 6 (all ps $<.01$, lsd test), and 7 ( $<<.05$, lsd test).

\section{DISCUSSION}

The present study, together with the previously cited earlier investigations, shows that a successive negative contrast effect is more likely to occur under conditions of relatively severe deprivation $(75 \%$ or $85 \%$ ad lib body weight, or $22 \mathrm{~h}$ food deprivation) than under conditions of less severe deprivation $(6 \mathrm{~h}$ food deprivation, or $98 \%, 95 \%$, or $90 \%$ ad lib body weight). These studies also show quite clearly that the contrast effect is more likely to occur toward the goal rather than toward the start section of the alley. In the present experiment and in the Cleland et al study (1969), significant contrast occurred only in the goal region; whereas, in the two Ehrenfreund studies, contrast was obtained in the run section. A possible explanation for this discrepancy among the studies may lay in the number of preshift trials given: 20 in Cleland et al (1969), 30 in this study, but 90 in Ehrenfreund \& Badia (1962) and 135 in Ehrenfreund (1971).

The interaction of deprivation state and contrast effects is interesting in two ways. First, the occurrence of negative contrast only under more severe deprivation conditions indicates that generalization decrement is unlikely to be the only factor involved in negative contrast (cf. Capaldi \& Lynch, 1967). This is so because more extreme deprivation states tend to enhance generalization (at least in other contexts, cf. Kalish \& Haber, 1965) and, therefore, more extreme deprivation states should oppose the occurrence of negative contrast if generalization decrement were the only factor involved.

Second, the effect of deprivation on negative contrast is consistent with the effect of deprivation on a number of other phenomena that are considered to be emotionally based. Specifically, the Amsel frustration effect appears to be directly related to degree of deprivation (McHose \& Ludvigson, 1964; Dunlap \& Frates, 1970); the conditions that favor the occurrence of the overlearning extinction effect include a large reward and high deprivation ( $80 \%$ body weight, Traupmann, 1972); the magnitude of reward extinction effect also seems more likely to occur under more severe deprivation states (Reynolds, Marx, \& Henderson, 1952; Zaretsky, 1965; Marx, 1967); patterning behavior (running slower on nonrewarded trials in a regular partial reinforcement sequence) also seems to be favored by more extreme deprivation states (Capaldi, 1972); and, finally, there is some slim evidence that the partial reinforcement extinction effect itself is favored by greater deprivation states (Mikulka \& Pavlik, 1966). The effect of deprivation on all of these phenomena is, in turn, consistent with an explanation framed within the Amsel (1958) approach-avoidance model.

\section{REFERENCES}

Amsel, A. The role of frustrative non-reward in noncontinuous reward situations. Psychological Bulletin, 1958, 55, 102-119. Capaldi, E. D. Enhancement of rats' single-alternation performance by high food deprivation. Psychonomic Science, 1972, 26, 9-12.

Capaldi, E. J., \& Lynch, D. Repeated shifts in reward magnitude: Evidence in favor of an associational and absolute (non-contextual) interpretation. Journal of Experimental Psychology, 1967, 75, 226-235.

Cleland, E. A., Williams, M. Y., \& Dilollo, V. Magnitude of negative contrast effect in relation to drive level. Psychonomic Science, 1969, 15, 121-122.

Crespi, L. P. Quantitative variation in incentive and performance in the white rat. American Journal of Psychology, 1942, 55, 467-517.

Dunlap, W. $P_{\text {, \& }}$ Frates, S. D. Influence of deprivation on the frustration effect. Psychonomic Science, 1970, 21, 1-2.

Ehrenfreund, D. Effect of drive on successive magnitude shift in rats. Journal of Comparative \& Physiological Psychology, 1971, 76, 418-423. 
Ehrenfreund, D., \& Badia, P. Response strength as a function of drive level and pre- and postshift incentive magnitude. Journal of Experimental Psychology, 1962, 63, 468-471

Flaherty, C. F., \& Davenport, J. W. Successive brightness discrimination in rats following regular versus random intermittent reinforcement. Journal of Experimental Psychology, 1972, 96, 1-9.

Kalish, H. I., \& Haber, A. Prediction of discrimination from generalization following variations in deprivation level. Journal of Comparative \& Physiological Psychology, 1965, 60, 125-128.

Marx, $M$. $\dot{H}$. Interaction of drive and reward as a determiner of resistance to extinction. Journal of Comparative \& Physiological Psychology, 1967, 64, 488-489.

McHose, J. H., \& Ludvigson, H. W. Frustration effect as a function of drive. Psychological Reports, 1964, 14, 371-374. Mikulka, P J \& Pavlik, W. B. Deprivation level, competing responses and the PRE. Psychological Reports, 1966, 1, 95-102.

Reynolds, B., Marx, M. H., \& Henderson, R. L. Resistance to extinction as a function of drive-reward interaction. Journal of Comparative \& Physiological Psychology, 1952, 45, 36-42.

Traupmann, K. L. Drive, reward, and training parameters, and the overlearning-extinction effect (OEE). Learning \& Motivation, 1972, 3, 359-368.

Zaretsky, H. H. Runway performance during extinction as a function of drive and incentive. Journal of Comparative \& Physiological Psychology, 1965, 60, 463-464.

(Received for publication March 1, 1973.) 